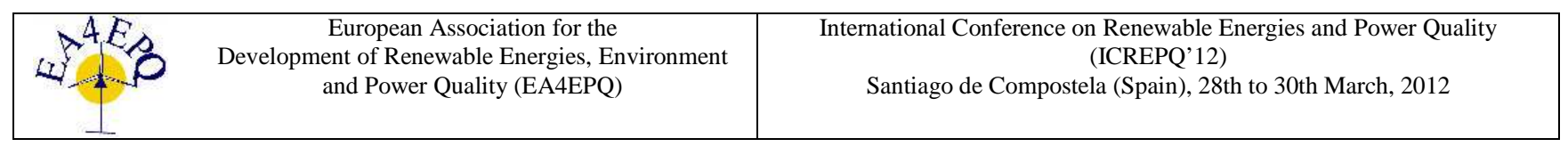

\title{
The Hot Spot phenomena in Shadowed ENR System
}

\author{
H. Benis ${ }^{1}$, H. Ben cheikh el hocine ${ }^{1}$, A. Bouden ${ }^{1}$ and M.Marir-Benabbas ${ }^{1}$ \\ ${ }^{1}$ Laboratoire de modélisation de dispositifs à énergie renouvelable \\ et nanométriques
}

Université Mentouri Constantine, Faculté des sciences de l'ingénieur

Département d'électronique, Alger

E mail : benis_halouma@yahoo.fr

\begin{abstract}
Model to represent the behaviour of photovoltaic (PV) solar cells in reverse bias is reviewed, concluding with a proposal of new model. This model comes from the study of avalanche mechanisms in PV solar cells, it can be adapted to PV cells witch reverse characteristic is dominated by avalanche mechanisms, and also dominated by shunt resistance. A simulation of shading effects in arrays with parallel series configuration has been done; an analysis has been made of the power dissipation with the influence of the number of shaded cells and the effect of shadowing degree.
\end{abstract}

\section{Key words}

Power dissipation, solar cells, reverse bias, hot spot, partial shadowing.

\section{Introduction}

Hot spot heating occur when a cell in a string of series connected cells is negatively biased and dissipates power in the form of heat instead producing electrical power. This happens when the current produced by given cell is lower than the string current. This can occur when the cell is shaded, or simply generates less current then the module $[1,2]$.

Shading part of a PV array has a very dramatic effect on its (P-V) curve. Shading even a very small fraction of the array may result in a very reduction of the array power. Partial shading can be occurred by utility poles, chimneys, trees, parts of other buildings ([3], [4]). Partial shading and electrical characteristics dispersion of PV modules have been accounted for $4.8 \%$ of losses in PV arrays [5].

Our study was based on the third cells type"C" [6], or was introducing a new expression of the avalanche voltage and en function of the shadowing degree " $F$ " defined as the ratio between the reduced Isc of the faulty cell and the standared Isc of the illumined cell. We made a study of thirty six cells six strings in parallel-series configuration. The purpose of this paper is to illustrate, by analyzing the effect of the number of the shaded cells and the effect of shadowing degree on the power dissipation.

For the resolution of the non linear equation our choice was the Dichotomy method proves to be the most appropriate.

\section{Solar cells models in reverse bias}

The impact of the applied system configuration on the energy yield of partially shadowed arrays has been widely discussed. [7]. There are several equations proposed in literature to simulate the behavior of PV cell in reverse bias. Most of them come from the conventional $\mathrm{I}-\mathrm{V}$ equation in the forward region modified in some way to introduce avalanche effects.

In 1982 Spirito and Albergamo [8] made a distinction between A-type cells, dominated in reverse bias by avalanche multiplication and B type cells, dominated by shunt resistance effects in reverse bias.

\section{A. Reverse bias equation for C type cells}

Later in 1986 Lopez Peneda [9] makes a distinction among three types of reverse I-V characteristics, depending if the main effect is a low shunt resistance or avalanche multiplication. The equation is similar to Albergamo's, but written in unique formula.

$$
I(V)=\left(I_{S C}-I\left(\exp \left(\frac{V}{A V_{T}}\right)-1\right)\right) M(V)-\left(\frac{V}{R_{s h}}\right)
$$

With

$$
M(V)=\frac{1}{1-\left(\frac{V}{V_{b r}}\right)^{x}}
$$


With the condition that:

- If $V>0 \Rightarrow M(V)=1$

- If $V<0 \Rightarrow M(V)>1$

- If $V=V_{b r}$ Multiplication coefficient $M(V)$ is infinite $M(V)=\infty$.

\section{B. Formulation of the simulation}

In order to model the solar cell curve, the current I, for a given voltage $\mathrm{V}$, must be computed individually for each value. Because the equation of the solar cell curve is not given in explicit form, numerical methods are normally used to determine the characteristic curve.

For $\mathrm{V}<0$ and neglecting the exponential terms:

$$
\begin{aligned}
& \left(\frac{\left(m-m_{o c}\right)}{m}+\frac{m_{o c} F}{m}\right)= \\
& \left(1-\frac{I_{0}}{I_{S C}}\left(\exp \left(\frac{V}{(n-1) A V_{T}}\right)-1\right)\right)\left(\frac{1}{M(V-1)}\right)-\left(\frac{(V-1)}{R_{s h} I_{S C}}\right)
\end{aligned}
$$

Equations (2) and (3)

$$
V_{b r}(F)=\left(\frac{(V-1)^{x}}{\frac{(V-1)}{R_{s h} I_{S C}}-\frac{\left(m_{o c} F\right)}{m}}\right)^{\frac{1}{x}}
$$

The power dissipated is [9]:

$$
P_{D}(V)=(V-1)(F) I_{S C} M(V-1)+\left(\frac{(V-1)^{2}}{R_{s h}}\right)
$$

This model comes from the study of avalanche mechanisms in PV solar cells, based on our study on the fallowing points:

-Influence of the shading degree " $F$ " on the power dissipation.

- Influence of the number of the shaded cells on the power dissipation.

-The maximum power dissipation.

\section{Results}

\section{1) Influence of the shading degree on the power dissipation.}

The power dissipation in a module of thirty six cells parallel-series connected which one is shaded is illustrate in the figure 1 for two values of the shunt resistance, one equal to $100 \Omega$ Fig. 1-a and the other is the optimal shunt resistance Fig. 1-b.

-the power dissipation will increase as shadowing degree increases.

-the maximum power dissipation obtained for $\mathrm{F}=0$ of the shadowing cell.

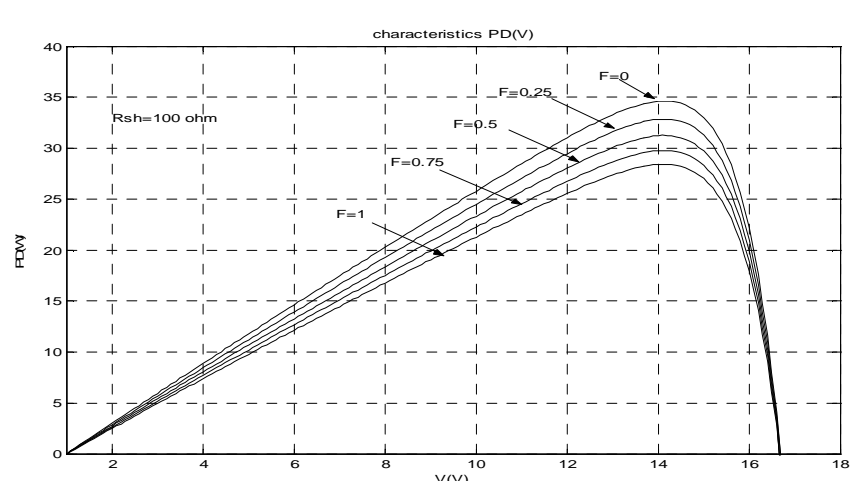

Fig. 1-a Influence of the shadowed degree on the power dissipation with $\mathrm{R}_{\mathrm{sh}}=100 \Omega$

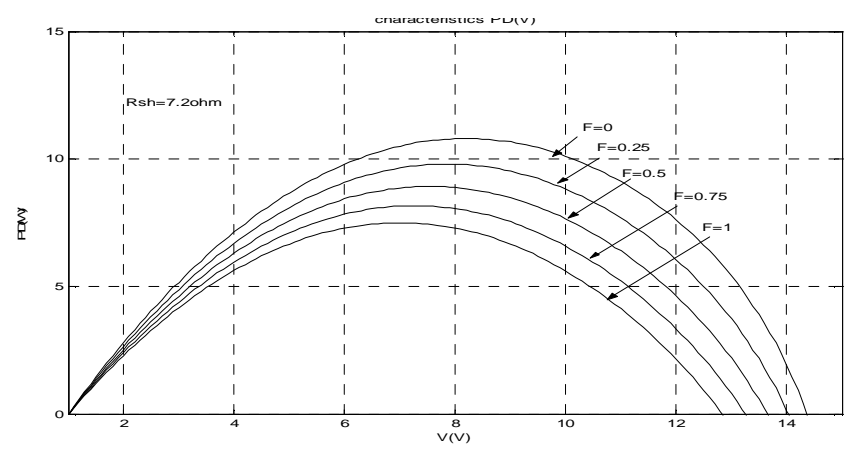

Fig. 1-b Influence of the shadowed degree on the power dissipation with $\mathrm{R}_{\mathrm{sh}}=7.2 \Omega$

2) Influence of the number of the shaded cells on the power dissipation

The fig. 2-a, fig. 2-b represents the influence of the shadowed cells for $\mathrm{F}=0$, it takes two cases of the shunt resistance, the optimal value and $100 \Omega$ respectively. It is seen that the power dissipation increases with increasing of the number of the shadowed cells and reached their maximum value for $\mathrm{m}_{\mathrm{oc}}=5\left(\mathrm{~m}_{\mathrm{oc}}\right.$ : number of the shadowed cells).

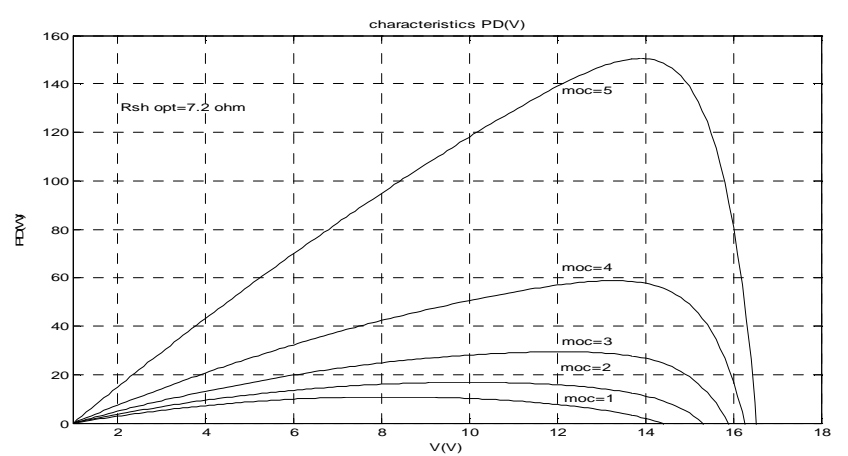

Fig. 2-a Influence of the number of the shadowed cells on the power dissipation with $\mathrm{R}_{\mathrm{sh}}=7.2 \Omega$ 


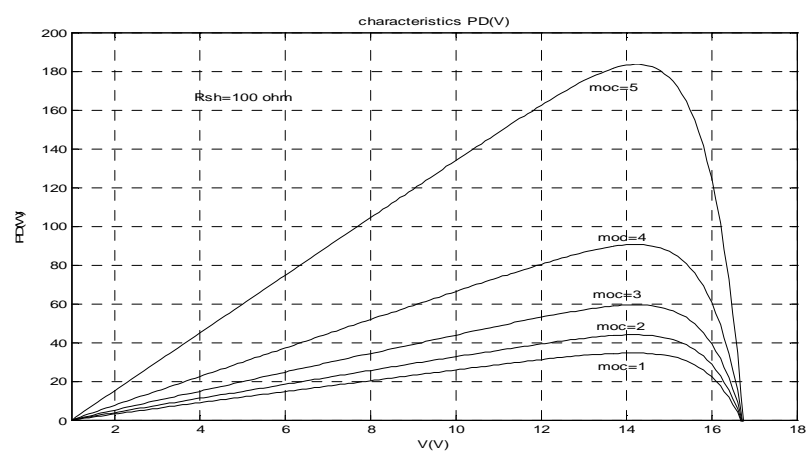

Fig. 2-a Influence of the number of the shadowed cells on the power dissipation with $\mathrm{R}_{\mathrm{sh}}=100 \Omega$

\section{3) The maximum power dissipation}

The Fig. 3 represents the maximum power dissipation obtained for five cells completely shadowed $(\mathrm{F}=0)$ in a module of 36 cells connected in parallel series, for a value of shunt resistance optimal $\mathrm{R}_{\mathrm{SH}} \mathrm{opt}=7.2 \Omega$

The number of shadowed cells critical for the power dissipation is a maximum $m_{o c}=m-1$.

$\mathrm{m}_{\mathrm{oc}}=$ number of channel in parallel -1

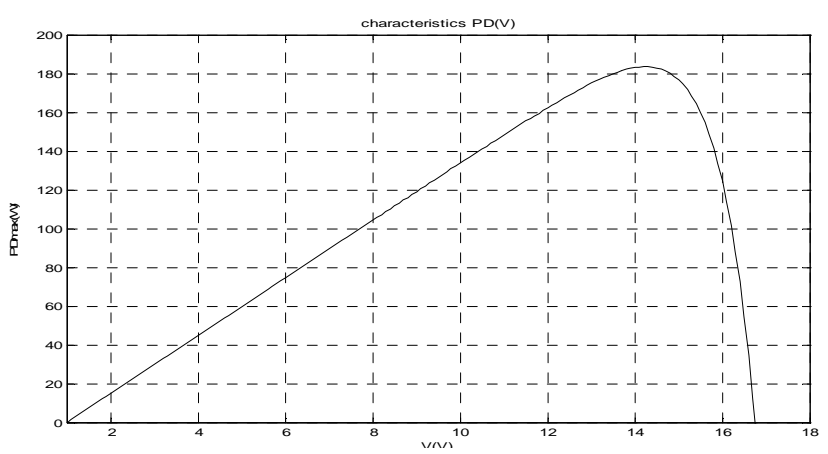

Fig. 3 The maximal power dissipation

\section{Conclusion}

Main conclusions of this work are addressed to emphasise the impotence of the power dissipation. Following conclusions are obtained from cases analysed with the simulation.

The increase of shading degree avec cell produces higher power dissipation.

Increase in the number of shaded cells causes higher power dissipation for the parallel series connection the higher power dissipation is experienced by the illuminated cells of the faulty parallel, giving a worst-case for $\mathrm{m}=\mathrm{m}_{\mathrm{oc}}-1$.

\section{References}

[1] D. Emolenbrock, K.A. Waddington, Emery, “ Hot spot susceptibility and testing of PV module", IEEE, 1991, pp.547.552.

[2] M. Del Buono, M. Armani, B. Pötz, D.Cattani, and

W.Sparber, "Performance measurements and monitoring of shadow effects on PV systems ". 23rd European Solar Energy Conference and Exhibition Valencia, Spain .2008.

[3] A. K. Sharma, R. Dwivedi, and S. K. Srivastava, "Performance analysis of a solar array under shadow condition", IEE Proc. Part G: Circuit, Devices and Systems, vol. 138, pp. 301-306, June 1991.

[4] W. Herrmann and W. Wiesner, "Modelling of PV modules - the effects on non-uniform irradiance on performance measurements with solar simulators ", in 16th European Photovoltaic Solar Energy Conf., 2000.

[5] D. Picault, B.Raison, J.Aguilera, J.De La Casa, "Changing photovoltaic array interconnections to reduce mismatch losses: a case study", IEEE, 2010.

[6] M.C.Alonso-Garcia, J.M.Ruiz, "Analysis and modelling the reverse characteristic of photovoltaic cells", Vol 90, issue 7-8, 2006, pp. 1105-1120.

[7] A. Woyte, J. Nijs, and R. Belmans, "Partial shadowing photovoltaic arrays with different systems configuration literature review and field test result". 2003, Vol. 74, Issue3, pp. 217-233.

[8] P.Spirito, V.Albergamo, "Reverse dissipation of shadowed or faulty cells in different away configuration", 4th, EC, pvsec, Italy, 1982.

[9]:C.F.Lopez Pineda,Solid wind technol 3, 85,1986. 